\title{
"The impact of DRG-based management of healthcare facilities on amenable mortality in the European Union"
}

$\begin{array}{ll} & \text { Rastislav Briestensky (iD) } \\ \text { AUTHORS } & \text { Aleksandr Ključnikov (i) } \\ & \mathbb{R}\end{array}$

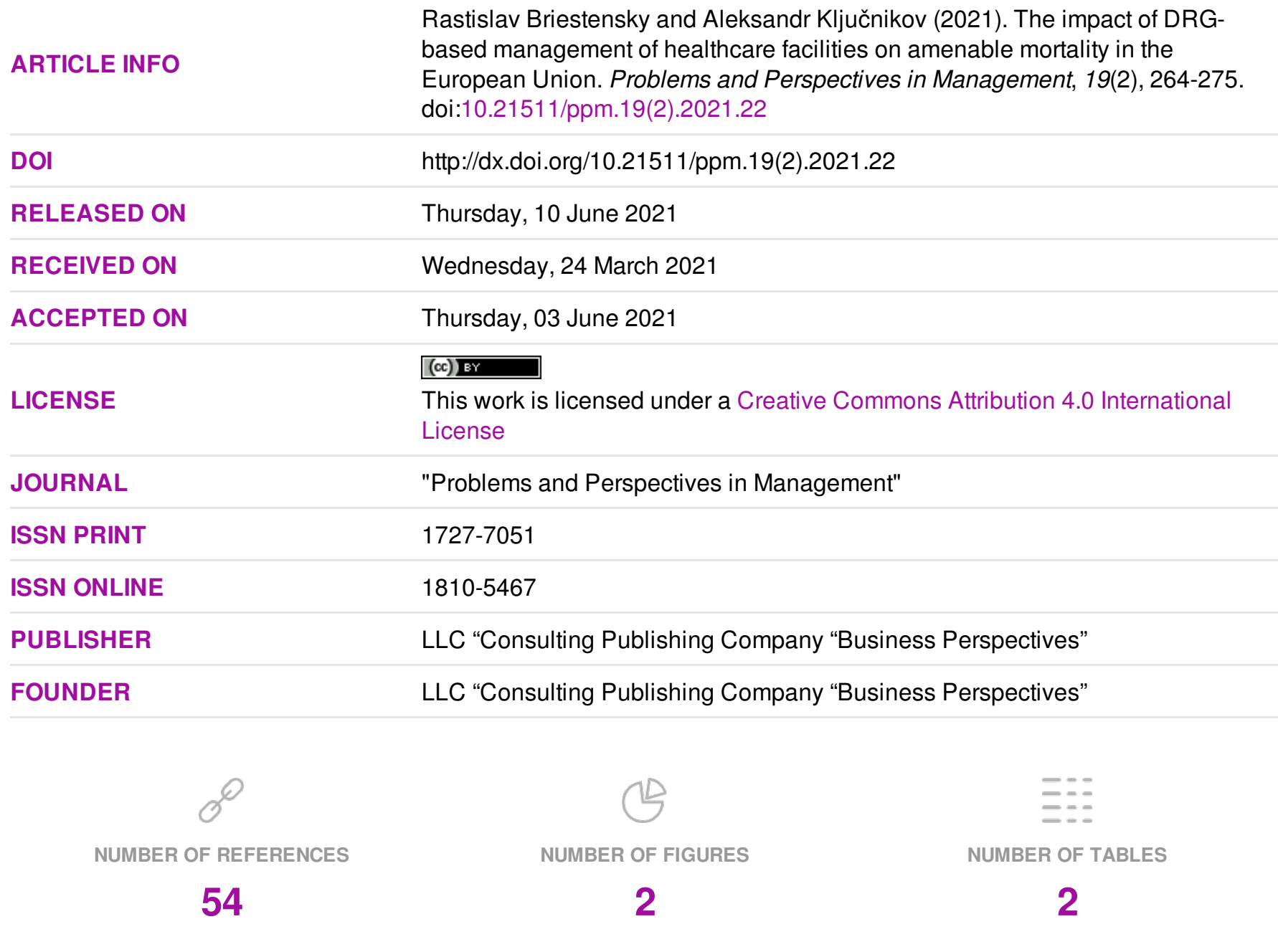

(c) The author(s) 2021. This publication is an open access article. 


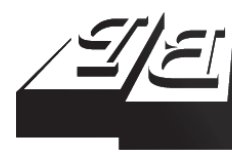

\section{BUSINESS PERSPECTIVES}

LLC "CPC "Business Perspectives" Hryhorii Skovoroda lane, 10, Sumy, 40022, Ukraine www.businessperspectives.org
Received on: $24^{\text {th }}$ of March, 2021 Accepted on: $3^{\text {rd }}$ of June, 2021 Published on: $10^{\text {th }}$ of June, 2021

() Rastislav Briestensky, Aleksandr Kljucnikov, 2021

Rastislav Briestensky, Ph.D. Student, Faculty of Economics and Business, Pan-European University, Bratislava, Slovak Republic. (Corresponding author)

Aleksandr Kljucnikov, Dr., Rector, Institute of Entrepreneurship and Marketing, University of Entrepreneurship and Law, Prague, Czech Republic.

\section{THE IMPACT OF DRG-BASED MANAGEMENT \\ OF HEALTHCARE FACILITIES ON AMENABLE MORTALITY IN THE EUROPEAN UNION}

\begin{abstract}
The quality of healthcare management can have a significant impact on the healthcare results achieved. Results of hospital treatment are directly related to the patient's health and quality of life, thus, it is necessary to examine the impact of different managerial approaches, including the ones related to financing, on indicators of healthcare provision. This article aims to determine whether there is a dependency between DRGbased (diagnosis-related groups) management of healthcare facilities and amenable mortality in the EU countries. Health expenditure per capita was measured in current international \$, the number of doctors, nurses, and beds per 1,000 inhabitants were determined as the input factors, while amenable mortality was determined as the outcome factor. The order of the efficiency of the input-output ratio of individual countries was defined using DEA analysis. Subsequently, the countries with the own healthcare financing method were ranked versus the countries with DRG-based management and financing by the mean value between groups using the Mann-Whitney U-test, while no statistically significant dependence was found between them ( $p$-value is $0.522-0.976$ for 2012-2017). Thus, even though DRG-based hospital management has various expected benefits, such as better managerial efficiency and transparency of financing, this approach to healthcare financing and management does not significantly impact amenable mortality.
\end{abstract}

Keywords

hospitals, hospital management efficiency, quality of healthcare, financing of healthcare, DRG-based management, amenable mortality

JEL Classification

I11, I15, L32

\section{INTRODUCTION}

For a proper analysis of the efficiency of healthcare financing and thus the effectiveness of hospital management in the EU countries, it is essential to evaluate the general environment and its specific regional characteristics. The national healthcare systems generally differ in several ways. The primary classification comes from the OECD (Organization for Economic Co-operation and Development). According to the method of financing, the OECD divides health systems as follows: voluntary insurance, social health insurance, and universal coverage. In addition, they add two other types regarding the current situation: compulsory national health insurance and residual programs. It is necessary to postpone the classical classification and create a classification based on the segmentation of healthcare services or the population. Based on this idea, Toth (2016) designed ten different models of healthcare systems. Each healthcare system has its different specifics, and therefore the selected groups of states should be taken into consideration when analyzing the current state or proposing any solution. 
Hospitals are open systems that operate dynamically outside the equilibrium point. Therefore, it is often possible to observe unpredictable environmental behavior (Diaz \& Castilla, 2017). Hospitals can be divided based on several criteria: by ownership - public and private hospitals; by financing - focus on profitability or non-profit; by educational activities - faculty and non-pedagogical hospitals; by hierarchical classification - primary, secondary and tertiary hospitals; by the degree of specialization - general and specialized hospitals; by the status of employees and physicians - hospital and personnel model (Asbu et al., 2020). There are many differences between hospitals, and each of them is somehow specific. Managers must understand these specifics to define the most suitable financing strategy. They may apply general procedures but should consider the specific characteristics of each hospital in the strategy.

When analyzing standard costing methods for individual hospital wards in Europe, the lack of standardized methodologies for determining the exact costs of hospital wards can be pointed out. A standardized costing methodology would facilitate comparisons, streamline economic evaluation within the department, and assist in the decision-making process regarding efficient resource allocation (Negrini et al., 2004). Each country in the European Union has a different system of healthcare financing. Several financing models are described in the literature: the Bismarck model, the Beveridge model, the National healthcare delivery model (a combination of the Bismarck model and the Beveridge model), and the Out-of-pocket model (Khaled \& Nessef, 2018). Since the 1990s, DRG-based (diagnosis-related group) management and financing was introduced in many countries to improve the efficiency of financial resources (Mihailovic et al., 2016).

Healthcare reforms force hospital managers to focus on the efficiency of financial resources. By evaluating resource efficiency, they can determine their performance (Giménez et al., 2019). It is estimated that there is a connection between hospital performance and the quality of health care. Efficiency is based on produced outputs concerning inputs (Schreyögg, 2019).

After evaluating performance, it is possible to reveal the strengths and weaknesses of each hospital or selected healthcare system (Setiawannie \& Rahmania, 2019). By finding this information, it is possible to compare individual hospitals and countries based on the selected criteria. In this way, it is possible to determine which of the factors influence hospital performance the most (Bhaduri, 2020). Amenable mortality, defined as premature death that can be avoided through the optimal quality of healthcare, is one of the essential outputs of the healthcare system (Gianino et al., 2017). There is a relationship between amenable mortality and the quality of healthcare. Amenable mortality is one of the indicators of healthcare quality (Kruk et al., 2018). The European Commission monitors it among the Member States to evaluate the healthcare system performance of a country (Weber \& Clerc, 2017).

In most cases, the influence of DRG is evaluated based on the selected factors of the general environment, transparency, and financial efficiency. Nevertheless, there is not enough evidence about the direct influence of DRG on medical performance indicators, such as amenable mortality in the European Union countries.

\section{LITERATURE REVIEW}

The hospital financing system is considered an essential part of their management (Gaspar et al., 2020). Among other shortcomings, some countries in the EU do not apply a comprehensive approach to their financial management. Given the above, sufficient reforms are needed in these areas. One of the possible changes can be the introduc- tion of DRG-based management and financing (Dubas-Jakóbczyk et. al, 2020). DRG-based financing classifies each patient's case according to the diagnosis and other characteristics. Payment for treatment is therefore based on DRG groups and used resources (WHO, 2012).

DRGs are considered to be tools for hierarchical cost control within the US private health in- 
surance system. At the same time, their application in the English national health service system may increase the productivity of hospital services. Additionally, it is established that DRGs boost competition within the German social health insurance system, and thus are viewed as tools for managing self-regulated providers. In this regard, DRG stimulates hybridization of a healthcare sector contributing to the update of less developed mechanisms that already exist in such a sector (Schmid et al., 2010). DRG-based financing systems provide better measurability of healthcare costs (European Commission, 2017). Better measurability brings more control over expenditures, as well as their possible direction in the desired way. Subsequently, managers can identify the strengths and weaknesses of financing, leading to a set of recommendations for streamlining financing (Tan et al., 2012). For this reason, it is necessary to distinguish healthcare between countries that have a DRG-based financing system and those that do not use such a system.

As each country usually uses a unique DRG system, it is crucial to know the purpose for which the whole system is designed. The professional domestic and foreign literature contains an analysis of each of these countries, from financing strategies to operational activities (Quentin et al., 2013). It is sufficient to understand which countries have established DRG financing systems, from which year, and for what purposes to assess the effectiveness of countries. DRG-related financing is used in the following countries: Estonia (since 2003), Finland (since 1995), France (since 1991), Netherlands (since 2005), Ireland (since 1992), Germany (since 2003), Poland (since 2008), Portugal (since 1984), Austria (since 1997), Spain (since 1996), Sweden (since 1995) and Great Britain (since 1992) (Busse et al., 2011).

If any country wants to introduce DRG-based management and financing, it can choose from the existing systems or create a specific version of the system (Kashilska \& Petkov, 2019). Each of the existing systems has its criteria of classification (Talaghir et al., 2018). As each country has different ways of providing health care and the structure of providers, it must choose specific criteria when implementing DRG (Milcent, 2021). Each country should make a separate study to set case weights to implement it; otherwise, it can create the wrong incentives (Mathauer \& Wittenbecher, 2013). According to these findings, it is possible to conclude that the implementation of this system is a process that requires proper setup. Therefore, when implementing this method of financing, it is essential to examine the state of healthcare providing of each country carefully, and the results can be hardly generalized (Stephani et al., 2017)

Every financing system implemented across the countries of the European Union has its strengths and weaknesses. DRG-based management and financing are applied across many countries, as it has many advantages such as financial transparency or the possibility to evaluate hospital performance. The application of the DRG system presupposes increased efficiency, and a reduction in the length of hospital stay (Mihailovic et al., 2016), transparent and fair allocation of financial resources, equal payments for equally demanding hospitalizations, higher payment for more demanding hospitalizations, unification of contractual relations between health insurance companies and health care providers, higher motivation to keep documentation on provided healthcare services and the possibility of measuring and comparing the productivity of hospitals (Ozorovský, 2016). DRG sets a cost ceiling beneath so that healthcare providers can reduce their costs (Sheaff et al., 2020). Nevertheless, this system can provide an incentive to transfer patients to home treatment sooner than if it was not in place. Therefore, the application of DRG may not have a clear medical benefit (Mihailovic et al., 2016). It can also be stated that DRG application does not always bring an increase in system efficiency (Cylus et al., 2017). When managers want to evaluate the efficiency of this system, they should consider the relationship between efficiency, equality, and equity (Chletsos \& Saiti, 2019).

Each country can have different characteristics that must be considered when comparing them. Medical tourism is one of the important ones. In terms of medical tourism, patients travel to other countries for medical procedures. Patients may be motivated by one or more of the following factors: lower prices, higher quality of services, the performance of specific actions not available in their own country, the possibility of connecting with holidays and convalescence in each country, 
etc. (Stewart, 2018). Health tourism can significantly impact measuring the performance of target countries, as these countries can't be included in the comparison. Data on the number of doctors, nurses, and beds per 1,000 inhabitants may be distorted within the statistics. Furthermore, this may affect financing, as these services are paid by patients and not by the hospital budget. Including these countries in the performance, comparison amends the results. According to several expert sources, Romania and Bulgaria can be considered among the countries most affected by health tourism (Zolfagharian et al., 2018, Lubowiecki-Vikuk \& Kurkowiak, 2017, Stewart, 2018, Badulescu et al., 2019, Frent \& Niculescu, 2018, Rizova, 2016).

Without measurement, it cannot be expected to improve hospital management quality to reach a high level (Quentin et al., 2019). In assessing effectiveness, the World Health Organisation (WHO) recommends focusing on inputs and outputs in healthcare. Therefore, it is a question of assessing whether, given the inputs to be interpreted, a particular country, region, or health facility achieves the optimal number of outputs. Based on the input-output-oriented analysis, the performance of health care systems can be measured. WHO methodology uses input-output evaluation of the effectiveness of hospitals (WHO, 2012). For this purpose, inputs and outputs must be selected to meet the objective of the research. Based on the above, it is possible to calculate hospital efficiency as a proportion of outputs to inputs.

Different input and output data were used. The data was selected mainly regarding the group of countries studied or based on theoretical knowledge to be verified. To compare states or determine the effectiveness in finding the ideal model of functioning, only those factors that are applicable in the environment of the European Union countries were used. The selection of factors can be based on the WHO recommendation. It uses some standard indicators, usually recalculated per 1,000 inhabitants or assigning them to a specific age group of the population. All indicators are in a standardized form and thus consider the structure of the population based on age and gender, the structure of the population in other countries, or individual national statistics standardized differently. These indicators include in particular: age-standardized mortality rate per 100,000 population, life expectancy at birth and the age of 65 , infant mortality, health expenditure per capita measures in PPP (purchasing-power-parity), number of doctors and nurses per 1,000 inhabitants, number of beds per 1,000 inhabitants, healthy years of life at the age of 65 (WHO, 2019).

Many authors presented the studies on this topic performed using Data Envelopment Analysis (DEA). Several studies work with different inputs and outputs, for example: number of beds, number of doctors, percentage of GDP spent on healthcare as inputs and life expectancy at birth, life expectancy adjusted for health, infant mortality rate as outputs (Asandului et al., 2014); number of beds, number of doctors as inputs and operating income, number of cases, days of hospitalization as outputs (Nistor et. al., 2017); number of beds, number of doctors, number of nurses, number of therapists as inputs and number of patients discharged during a given period as outputs (Dénes et. al., 2018); number of doctors, number of nurses, number of beds as inputs and life expectancy at birth, survival rate of infants as outputs (Önen \& Sayın, 2018); number of beds, number of medical staff, number of CT devices, number of magnetic resonance devices, number of all medical devices as inputs and bed occupancy rate, average treatment time as outputs (Stefko et al., 2018); expenditure on health, lifestyle, GDP per capita, education, number of beds, number of nurses and doctors as inputs and life expectancy and healthy life at birth and at the age of 65 , amenable mortality as outputs (Medeiros \& Schwierz, 2015).

\section{AIMS, HYPOTHESIS AND METHODOLOGY}

Healthcare financing is a critical factor that influences hospital management. This paper focuses on the effectiveness of healthcare financing in countries with more funds but cannot manage them efficiently.

The aim is to determine whether there is a significant dependency between DRG-based (diagnosis-related groups) management of healthcare facilities and amenable mortality in the European Union countries. The literature review allows as- 
suming that DRG-based managed healthcare systems can be more efficient than others. Based on the literature review and the aim of the paper, the following hypothesis was formulated:

HO: There is no statistically significant difference between the mean value of the order of countries with DRG-based managed healthcare systems and countries with the other unique healthcare financing system according to the selected model.

The alternative hypothesis states the following:

H1: There is a statistically significant difference between the mean value of the order of countries with DRG-based managed healthcare systems and countries with other unique healthcare financing systems according to the selected model.

In this research, the hospital management approaches are to be examined at the level of individual countries, not at the level of individual facilities, because of the assumption that individual hospitals within the selected country will not have significant differences in the areas of financing and legislation.

The countries were divided into two groups for this research: 1. States with DRG-based healthcare management and financing and 2. States with unique healthcare financing systems. To improve the accuracy of the results, Bulgaria and Romania were excluded from the research sample, while the main reason was the extensive development of medical tourism.

Input data represent input values that affect the efficiency of hospital management. With a low number of beds, there is a higher waiting time for procedures and other negative consequences. With an excessive number, the occupancy of hospitals is lower, which increases costs and reduces the efficiency of use. Based on the WHO methodology and the literature review, a unique combination of inputs and outputs was selected. Financial factors, human resources, and equipment were defined as the inputs, and such healthcare quality factors as mortality, life expectancy, and treatment time were considered as the outputs.
Focusing on the differences in the financial background of the selected states, health expenditure per capita measured in PPP was selected as the first input. The impact of the number of doctors and nurses involved in the healthcare system can also be significant. By examining the effectiveness, it is possible to determine which countries have the most effectively used medical staff. The number of physicians per 100,000 inhabitants and the number of nurses per 100,000 inhabitants were selected as the other inputs. The number of hospital beds per 1,000 inhabitants was selected as the last input to consider the differences in hospital resources, as it can differ in selected countries. Amenable mortality as a quality indicator was selected as the measured output.

The model of inputs (Health expenditure per capita measures in PPP, Number of physicians per 100,000 inhabitants, Number of nurses per 100,000 inhabitants, and Number of beds per 1,000 inhabitants) and output (Amenable mortality) was created to evaluate the performance of management of healthcare systems.

The research uses the EUROSTAT data about all inputs and outputs for all countries for 20122017. Data from databases are adjusted to reflect the structure of the EU population or conversion to 100,000 or 1,000 inhabitants. The missing data were completed from the OECD database.

The Data Envelopment Analysis method, a method that is recently being used in healthcare (Asandului et al., 2014, Medeiros \& Schwierz, 2015, Nguyen \& Zelenyuk, 2020), was applied as the primary research method. It is a nonparametric method that compares efficiency between inputs and outputs (WHO, 2000). In this way, it helps to identify the factors associated with successful hospital management. The method can be input-oriented or output-oriented (Ahmed et al., 2019). In the case of hospitals, it helps to identify how the specific inputs affect the outputs. When comparing within the EU, it is possible to determine what change in inputs can be used to improve outputs and which countries work most effectively concerning the selected inputs and outputs. From the data obtained, it is possible to propose a set of basic recommendations for other countries, which will result in increased efficiency of hospital man- 
agement. The input-oriented version is used in the research to determine how to minimize inputs to achieve the desired outputs.

DEA analysis is based on the decision-making units (DMU). In this case, each DMU represents a particular country. Efficiency is calculated based on the data provided and is limited by it. The calculation of the DEA analysis is based on two steps: 1. The limit is determined; 2 . The efficiency score obtained after comparing the inputs and outputs that are located at the most efficient DMU is assigned to each DMU. The ratio of outputs to inputs is used to calculate the efficiency of each DMU at a distance from the limit of the most efficient DMU. Assume that there are $n$ DMUs, $m$ inputs, and $s$ outputs. The efficiency score of the tested DMU is obtained by calculating the proposed model. The above-presented approach is run $n$ times to identify the relative efficacy scores of all DMUs. Each DMU selects input and output scales that maximize its efficiency score.

The Mann-Whitney $U$-test, a nonparametric equivalent of the $t$-test (MacFarland \& Yates, 2016), is used with nonparametric data. Using this test, it can be determined whether there is a relationship between two dependent groups of data (Stehlíková, 2009).

There are considered measurements from data group A from the set $x_{1}, x_{2}, x_{3}, \ldots, x_{n 1}$ and from data group $\mathrm{B}$ from the set $y_{1}, y_{2}, y_{3}, \ldots, y_{n 2}$. Subsequently, measurements are arranged in size from the smallest value to the largest, thus obtaining a mixed selection $z_{1}, z_{2}, z_{3}, \ldots, z_{n}$, while $n=n 1+n 2$. The values $1, \ldots, n$ are then assigned to the individual values according to their order. If any of the values are repeated, they are assigned an order calculated from the average of the orders of the repeating value. It is possible to test the criterion from the relationship $U=\min \left(U_{a}, U_{b}\right)$. Subsequently, using the tables, this value can be compared using the tables for the appropriate $n_{1}$ and $n_{2}$, where the selected value of statistical significance is $\alpha$.

If $U<U_{\left(\alpha, n_{1}, n_{2}\right)}$, hypothesis $H_{0}$ is rejected.

If $U>U_{\left(\alpha, n_{1}, n_{2}\right)}$, hypothesis $H_{0}$ cannot be rejected.

\section{RESULTS AND DISCUSSION}

Using DEA analysis and selected model of inputs (Health expenditure per capita measures in PPP, Number of physicians per 100,000 inhabitants, Number of nurses per 100,000 inhabitants and beds per 1,000 inhabitants) and output (Amenable mortal$i t y$ ), thetaOpt values are calculated, which determine the degree of efficiency between selected countries using predefined input and output data. The higher the value, the better the efficiency. A higher thetaOpt value means that the country uses its resources more optimally. The maximum value of the thetaOpt is 1 . The country that reaches thetaOpt value 1 each year has the most optimal use of resources compared to other selected countries. DRG-based management and financing are focused on optimizing financing, and therefore the optimization of the input-output ratio is used instead of focusing only on output indicators. An overview of individual countries and the development of the situation for individual years together with data on the implementation or failure to implement DRG-based management and financing system are presented in Table 1 . The value of thetaOpt was rounded to 3 decimal places.

After calculating thetaOpt value, a ranking of countries according to the optimality of their healthcare based on selected inputs and outputs for each year separately was created. The country with the highest value of thetaOpt is at the first place. The evaluation was performed for each year separately. Subsequently, countries were divided into two groups according to whether they have DRG-based management and financing systems in place. Two groups of countries with an assigned sequence number 1-26 were created. Figure 1 presents the value of thetaOpt in selected EU countries according to the selected model.

Figure 1 shows which countries have better efficiency based on the selected model for the last year (the period of evaluation is 2012-2017). While Latvia and Great Britain are the countries with the best results, Austria, Germany, and France have lower efficiency of selected inputs/output models. It must be mentioned that there is a dependency between the performance (thetaOpt) and amenable mortality. Evaluation of performance shows which countries have better amenable mortality considering their inputs. Despite this, country 
Table 1. ThetaOpt value for selected EU countries for 2012-2017

\begin{tabular}{|c|c|c|c|c|c|c|c|}
\hline \multirow{2}{*}{ Country } & \multirow[b]{2}{*}{ DRG } & \multirow{2}{*}{2012} & \multirow{2}{*}{2013} & \multirow{2}{*}{2014} & & \multicolumn{2}{|c|}{ Source: Authors' elaboration. } \\
\hline & & & & & 2015 & 2016 & 2017 \\
\hline Estonia & Yes & 0.767 & 0.81 & 0.822 & 0.823 & 0.845 & 0.822 \\
\hline Finland & Yes & 0.418 & 0.434 & 0.462 & 0.474 & 0.544 & 0.657 \\
\hline France & Yes & 0.299 & 0.302 & 0.311 & 0.312 & 0.316 & 0.324 \\
\hline The Netherlands & Yes & 0.481 & 0.464 & 0.478 & 0.553 & 0.564 & 0.554 \\
\hline Ireland & Yes & 0.919 & 0.887 & 0.879 & 0.79 & 0.759 & 0.704 \\
\hline Germany & Yes & 0.33 & 0.331 & 0.327 & 0.334 & 0.328 & 0.315 \\
\hline Poland & Yes & 0.912 & 0.917 & 0.872 & 0.871 & 0.87 & 0.896 \\
\hline Portugal & Yes & 0.711 & 0.697 & 0.726 & 0.71 & 0.737 & 0.698 \\
\hline Austria & Yes & 0.271 & 0.271 & 0.277 & 0.289 & 0.295 & 0.292 \\
\hline Spain & Yes & 0.631 & 0.625 & 0.624 & 0.631 & 0.635 & 0.624 \\
\hline Sweden & Yes & 0.742 & 0.757 & 0.751 & 0.799 & 0.814 & 0.843 \\
\hline Great Britain & Yes & 0.857 & 0.858 & 0.875 & 0.944 & 0.985 & 0.987 \\
\hline Belgium & No & 0.39 & 0.4 & 0.386 & 0.378 & 0.368 & 0.368 \\
\hline Cyprus & No & 0.634 & 0.571 & 0.581 & 0.642 & 0.584 & 0.617 \\
\hline Czechia & No & 0.551 & 0.56 & 0.547 & 0.563 & 0.544 & 0.562 \\
\hline Denmark & No & 0.71 & 0.688 & 0.784 & 0.846 & 0.824 & 0.79 \\
\hline Greece & No & 0.621 & 0.612 & 0.674 & 0.682 & 0.667 & 0.66 \\
\hline Croatia & No & 0.7 & 0.675 & 0.709 & 0.739 & 0.715 & 0.706 \\
\hline Lithuania & No & 0.768 & 0.774 & 0.756 & 0.841 & 0.865 & 0.789 \\
\hline Latvia & No & 1 & 1 & 1 & 1 & 1 & 1 \\
\hline Luxembourg & No & 0.387 & 0.431 & 0.361 & 0.394 & 0.415 & 0.443 \\
\hline Hungary & No & 0.869 & 0.833 & 0.844 & 0.918 & 0.867 & 0.889 \\
\hline Malta & No & 0.605 & 0.504 & 0.553 & 0.52 & 0.527 & 0.543 \\
\hline Slovakia & No & 0.803 & 0.83 & 0.798 & 0.847 & 0.819 & 0.851 \\
\hline Slovenia & No & 0.539 & 0.547 & 0.532 & 0.563 & 0.5 & 0.491 \\
\hline Italy & No & 0.571 & 0.566 & 0.581 & 0.614 & 0.592 & 0.591 \\
\hline
\end{tabular}

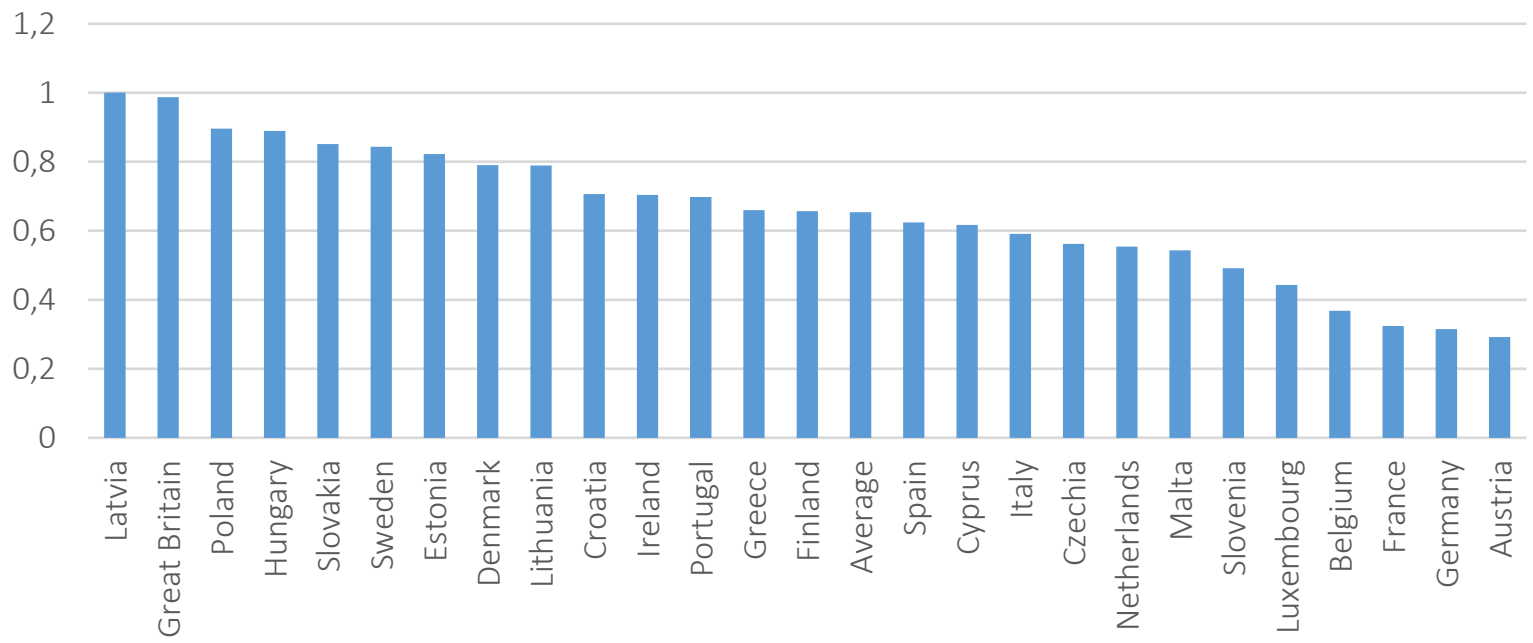

Figure 1. ThetaOpt value in selected EU countries according to the selected model

values by amenable mortality can be different, e.g., bers 1-26 for each year (the period of evaluation Latvia, with the best performance of inputs and is 2012-2017) was made. The calculation for each outputs, has the worst value of amenable mortality. year was performed separately. For each year, countries were divided into two groups by hospital After performing DEA analysis, an order of all financing: 1. States with DRG-based management countries based on their performance with num- and financing and 2. States with a unique financ- 


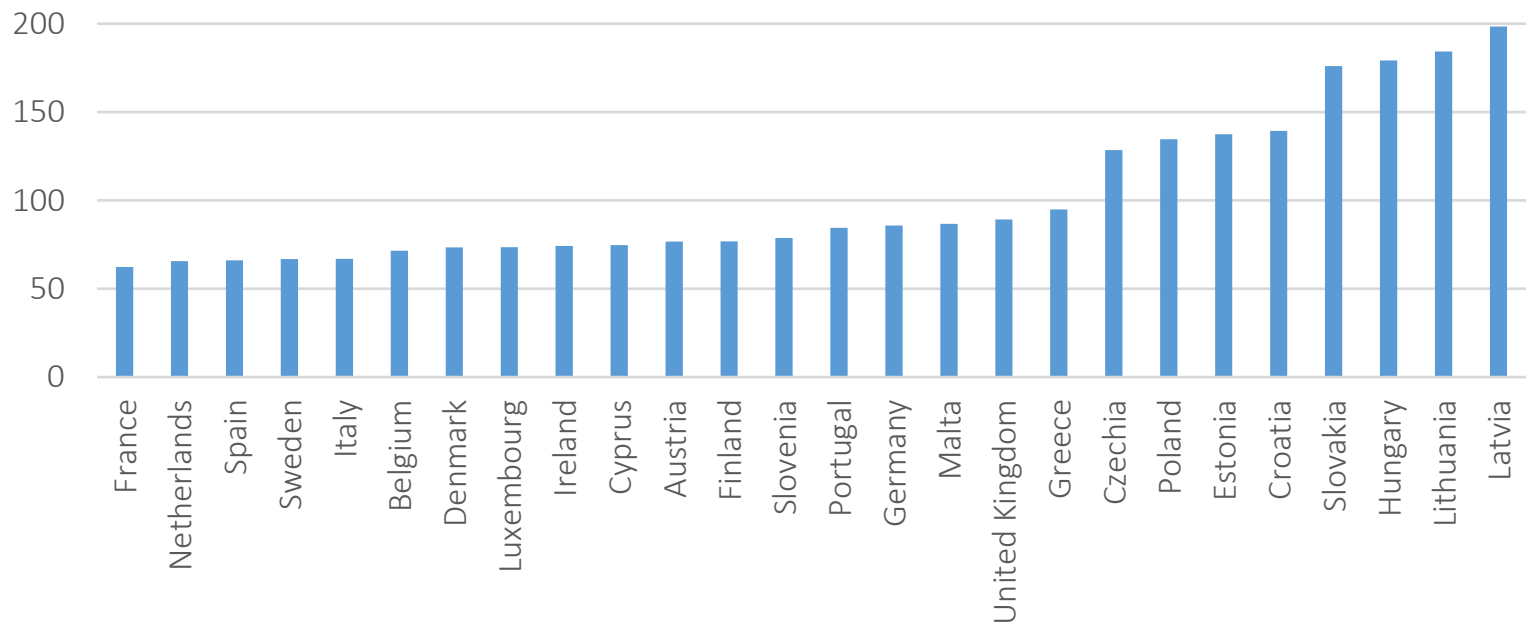

Figure 2. Amenable mortality (standardized death rate per 100000 inhabitants) of selected countries

ing system. After that, the Mann-Whitney U-Test was used to determine the existence of a significant difference in mean efficacy between the two groups. After its evaluation for individual years, Table 2 was created.

$U$ represents the value of the test statistic, and $p$-value expresses statistical significance. Since $p$ is greater than 0.05 , the hypothesis $\mathrm{HO}$ is confirmed, the alternative hypothesis $H 1$ is rejected. The results give a significant finding - DRGbased healthcare management and financing system does not affect amenable mortality in the European Union countries. As already mentioned, several studies have shown the positive impact of the DRG on transparency, possibilities for evaluating financing, transparency in the use of funds spent, and other factors. However, this system did not bring any significant changes in the medical field in the form of the impact on amenable mortality. However, this does not mean that the application of this system is unnecessary or ineffective.

As each of the countries has a different healthcare system, it is not possible to analyze all of them in detail. Therefore, some factors can significantly impact strategy creation, and managers should focus on them. DEA analysis showed that there was no statistically significant difference between the effectiveness of countries with their financing systems and DRG-based management and financing focusing on deaths from treatable diseases. It can be assumed that DRG will have benefits in each established country. After increasing transparency, it will be easier for managers to manage financial flows, analyze them and suggest possible solutions.

The research was focused on the optimality of the use of inputs in relation to amenable mortality. While many studies were focusing on DRGs impact on the specific factors, specific diseases, medical departments, or countries (Dewilde et al., 2018; Mihailovic et al., 2016; Fässler et al., 2015; Klein-Hitpaß \& Scheller-Kreinsen, 2015), none of them was focused on DRG neither in combination with amenable mortality or on the application in the conditions of the European Union countries. For this reason, the research results can be considered a new contribution to the financial management of hospitals.

DRG implementation research was focused mainly on describing the benefits based on knowl-

Table 2. Mann-Whitney U-Test of the effectiveness of selected EU countries

Source: Authors' elaboration.

\begin{tabular}{l|c|c|c|c|c|c}
\hline \multicolumn{1}{c}{ Years } & $\mathbf{2 0 1 2}$ & $\mathbf{2 0 1 3}$ & $\mathbf{2 0 1 4}$ & $\mathbf{2 0 1 5}$ & $\mathbf{2 0 1 6}$ & $\mathbf{2 0 1 7}$ \\
\hline$U$ & 77 & 82 & 80 & 71 & 80 & 82 \\
\hline$p$-value & 0.97606 & 0.93624 & 0.85716 & 0.52218 & 0.85716 & 0.93624 \\
\hline
\end{tabular}


edge of hospital financing (Ozorovský et al., 2016, Mihailovic et al., 2016, Cylus et al., 2017). As this is a way of financing hospitals, research was focused on measuring its effectiveness. The ratio of inputs and outputs was used for this purpose. Commonly used indicators of used sources (financing, medical staff) were usually as inputs and amenable mortality was considered an output being the main quality indicator. Asandului et al. (2014), Önen and Sayın (2018), Stefko et al. (2018), Medeiros and Schwierz (2015) used various combinations of inputs and outputs. Used indicators respected WHO recommended methodology. If the research focused only on optimization in general, several models would have to be created, or another model that would consider other output data within the DEA analysis to be chosen. Potential years of life lost can be chosen as an output in the future model, but this factor can be influenced not only by healthcare but also by lifestyle, location of a country, culture, financial situ- ation, education level, environmental factors, and others (WHO, 2019). For this reason, amenable mortality is the most appropriate indicator to examine optimization.

When comparing thetaOpt values, which represent efficiency and amenable mortality, it is possible to point to another new finding. The country with the highest efficiency rate may not have the lowest amenable mortality. As countries increase the number of financial resources and other resources spent on healthcare, the rate of optimization decreases from a certain value. Based on the above, it is possible to explain, for example, the highest efficiency rate of Latvia, which also has the highest amenable mortality. Since Mihailovic et al. (2016), Ozorovský (2016), Sheaff et al. (2020), and Cylus et al. (2017) so far have been focused mainly on the optimal use of resources by introducing DRG, data was used for envelopment analysis to evaluate the efficiency of used sources.

\section{CONCLUSION}

The influence of DRG on the selected factors of the general environment, transparency, and financial efficiency was evaluated. Nevertheless, there is not enough evidence about the direct influence of DRG on medical performance indicators, such as amenable mortality in the European Union countries.

This article aimed to determine whether there is a significant dependency between DRG-based (diagnosis-related groups) management of healthcare facilities and amenable mortality in the European Union countries. Health expenditure per capita measured in PPP, the number of doctors, nurses, and beds per 1,000 inhabitants were determined as the input factors, while amenable mortality was determined as the outcome factor.

The order of the efficiency of the input-output ratio of individual countries was defined using DEA analysis. Subsequently, the countries with the own healthcare financing method were ranked versus the countries with DRG-based financing by the mean value between groups using the Mann-Whitney $U$-test. The main finding is as follows: there is no statistically significant difference between the mean value of the order of countries with DRG-based healthcare management and financing and countries with the other unique healthcare financing system according to the selected model ( $p$-value is 0.522 0.976 for 2012-2017). Even though DRG-based management and financing have various expected benefits, such as transparency of financing, this approach to healthcare financing and management does not significantly impact amenable mortality.

If any country in the European Union decides to implement DRG-based management and financing management, there can be expected that this change will not significantly influence (improve or worsen) the efficiency set by the selected model of selected inputs and outputs.

The research has some limitations, which are connected with the use of the secondary data from the selected countries of the European Union with generally similar healthcare financing systems. For further 
research, it can be recommended to use another DEA model, e.g., using potential years of life lost, and/ or compare the countries from other regions. Despite conclusions and recommendations, there should be noted that the existing methodology can hardly quantify the value of the health of the population. Therefore, much more attention should be paid to this aspect.

\section{AUTHOR CONTRIBUTIONS}

Conceptualization: Aleksandr Kljucnikov.

Data curation: Rastislav Briestensky.

Formal analysis: Aleksandr Kljucnikov.

Investigation: Rastislav Briestensky.

Methodology: Aleksandr Kljucnikov.

Project administration: Aleksandr Kljucnikov.

Resources: Rastislav Briestensky.

Software: Rastislav Briestensky.

Supervision: Aleksandr Kljucnikov.

Validation: Rastislav Briestensky.

Writing - original draft: Rastislav Briestensky.

Writing - review \& editing: Aleksandr Kljucnikov.

\section{REFERENCES}

1. Ahmed, S., Hasan, M. Z., MacLennan, M., Dorin, F., Ahmed, M. W., Hasan, M. M., Hasan, S. M., Islam, M. T., \& Khan, J. M. A. (2019). Measuring the efficiency of health systems in Asia: a data envelopment analysis. BMJ Open, 9(3), e022155. http://dx.doi.org/10.1136/bmjopen-2018-022155

2. Asandului, L., Roman, M., \& Fatulescuet, P. (2014). The efficiency of healthcare systems in Europe: A data envelopment analysis approach. Procedia Economics and Finance, 10, 261-268. https://doi.org/10.1016/S22125671(14)00301-3

3. Asbu, E. Z., Masri, M. D., \& Naboulsi, M. A. (2020). Determinants of Hospital Efficiency: A literature review. International Journal of Healthcare, 6(2), 4453. https://doi.org/10.5430/ijh. v6n2p44

4. Badulescu, A. V., Badulescu, A., Ardelean, S. V., \& Teusdea, A. F. (2019). Could Romania be a player on the global medical tourism market? Annals of the University of Oradea, Economic Science Series, 28(1). Retrieved from https:// web.a.ebscohost.com/abstract?site
$=$ ehost\&scope $=$ site $\&$ jrnl $=1222569$ $\mathrm{X} \& \mathrm{AN}=138244676 \& \mathrm{~h}=\mathrm{F} \% 2 \mathrm{fVwFi}$ Upr1kmAEPeCpY\%2btvr62QFo\% 2baun\%2b5fMwAj\%2fEosc8UdhQ SB4wR6WevN08F\%2bConGITrR $\mathrm{kB} \% 2 \mathrm{fnxMEpx} 6 \mathrm{MDvMw} \% 3 \mathrm{~d} \% 3 \mathrm{~d}$ \&crl $=$ c\&resultLocal $=$ ErrCrlNoRes ults\&resultNs=Ehost\&crlhashurl= login.aspx\%3fdirect $\% 3$ dtrue $\% 26 \mathrm{p}$ rofile $\% 3$ dehost $\% 26$ scope $\% 3$ dsite $\%$ 26authtype\%3dcrawler\%26jrnl\%3 d1222569X\%26AN\%3d138244676

5. Barouni, M., Ahmadian, L., Anari, H. S., \& Mohsenbeigi, E. (2020). Investigation of the impact of DRG based reimbursement mechanisms on quality of care, capacity utilization, and efficiencyA systematic review. International Journal of Healthcare Management, 1-12. https://doi.org/10.1080/2047 9700.2020 .1782663

6. Bhaduri, S. D. (2020). Germany: Health Care System Overview and SWOT Analysis. International Health Care Systems, 73(10), 36-39. Retrieved from http://articles. theindianpractitioner.com/index. php/tip/article/view/1069

7. Busse, R., Geissler, A., Wuentin, W., \& Wiley, M. (2011). Diagnosticrelated groups in Europe. Berkshire, England: Open University Press. Retrieved from https://www. euro.who.int/_data/assets/pdf file/0004/162265/e96538.pdf

8. Chletsos, M., \& Saiti, A. (2019). Financing Hospitals. Strategic Management and Economics in Health Care, 25, 207-232. doi. org/10.1007/978-3-030-35370-4

9. Cylus, J., Papanicolas, I, \& Smith, P. C. (2017). How to make sense of health system efficiency comparisons? (Policy Brief 27). Copenhagen, Denmark: WHO Regional Office for Europe. Retrieved from https://www.euro.who.int/_data/ assets/pdf_file/0005/362912/ policy-brief-27-eng.pdf?ua=1

10. Dewilde, S., Annemans, L., Pincé, H., \& Thijs, V. (2018). Hospital financing of ischaemic stroke: determinants of funding and usefulness of DRG subcategories based on severity of illness. BMC health services research, 18(1), 1-10. https://doi.org/10.1186/ s12913-018-3134-6

11. Dénes, R. V., Koltai, T., \& Dénes, Z. (2018). The effect of complicated cases on the efficiency of musculoskeletal in-patient rehabilitation units in Hungarian healthcare systems. 25th International EurOMA Conference. Retrieved from http://euroma2018. 
org/wp-content/uploads/proceeding/438_374_2.pdf

12. Diaz, C., \& Castilla, R. (2017). The Hospital: A Complex Adaptive System. Asian Journal of Medicine and Health, 5(1), 1-5. doi.org/ 10.9734/AJMAH/2017/34421

13. Dubas-Jakóbczyk, K., Albreht, T., Behmane, D., Bryndova, L., Dimova, A., Džakula, A., Habicht, T., Murauskiene, L., Scîntee, S.G., \& Smat, M. (2020). Hospital reforms in 11 Central and Eastern European countries between 2008 and 2019: A comparative analysis. Health Policy, 124(4), 368-379. https://doi.org/10.1016/j.healthpol.2020.02.003

14. European Commission. (2017). EuroDRG - Diagnosis-Related Groups in Europe: towards Efficiency and Quality (Project Report). Retrieved from https://cordis. europa.eu/project/id/223300

15. Fässler, M., Wild, V., Clarinval, C. Tschopp, A., Faehnrich, J. A., \& Biller-Andorno, N. (2015). Impact of the DRG-based reimbursement system on patient care and professional practise: perspectives of Swiss hospital physicians. Swiss Medical Weekly, 145. https://doi. org/10.4414/smw.2015.14080

16. Frent, C., \& Niculescu, A. (2018). Estimating the economic contribution of medical tourism in Romania based on the tourism satellite account data. Revista de turism-studii si cercetari in turism, 26. Retrieved from http://www. revistadeturism.ro/rdt/article/ view/419

17. Gaspar, K., Portrait, F., Hijden, E., \& Koolman, X. (2020). Global budget versus cost ceiling: a natural experiment in hospital payment reform in the Netherlands. The European Journal of Health Economics, 21(1), 105-114. https://doi. org/10.1007/s10198-019-01114-6

18. Gianino, M. M., Lenzi, J., Fantini, M. P., Ricciardi, W., \& Damisni, G. (2017). Declining amenable mortality: a reflection of health care systems? BMC Health Services Research, 17(1), 1-8. Retrieved from https://bmchealthservres.biomedcentral.com/track/pdf/10.1186/ s12913-017-2708-z.pdf
19. Giménez, V., Keith, J. R., \& Prior, D. (2019). Do healthcare financing systems influence hospital efficiency? A metafrontier approach for the case of Mexico. Health Care Management Science, 22(3), 549-559. https://doi.org/10.1007/ s10729-019-9467-9

20. Kashilska, Y., Petkov, A. (2019). Effects of the introduction of DRG in the healthcare systems of European countries. Medical biology studies, clinical studies, social medicine and health care, 3(1), 67-73. Retrieved from http://www. sandtr.org/journal/1/61.pdf

21. Khaled, L. N., \& Nessef, L. (2018). Overview of World Health Systems. International Journal of Scientific and Research Publications, 8(9), 511-515 Retrieved from http://www.ijsrp.org/researchpaper-0918/ijsrp-p8171.pdf

22. Klein-Hitpaß, U., \& Scheller-Kreinsen, D. (2015). Policy trends and reforms in the German DRG-based hospital payment system. Health Policy, 119(3), 252-257. https://doi.org/10.1016/j. healthpol.2015.01.006

23. Kruk, M. E., Gage, A.D., Joseph, N.T., Danaei, G., Garcia-Saiso, S., \& Salomon, G.A. (2018). Mortality due to low-quality health systems in the universal health coverage era: a systematic analysis of amenable deaths in 137 countries. The Lancet, 392(10160), 2203-2212. https://doi.org/10.1016/s01406736(18)31668-4

24. Lubowiecki-Vikuk, A., \& Kurkowiak, J. (2017). Medical tourism potential of Central and Eastern Europe: Attempt at classification. CBU International Conference Proceedings, 5, 286-293. http://dx.doi. org/10.12955/cbup.v5.940

25. MacFarland, T. W., \& Yates, J. M. (2016). Introduction to nonparametric statistics for the biological sciences using R. Cham: Springer International Publishing. doi. org/10.1007/978-3-319-30634-6

26. Mathauer, I., \& Wittenbecher, F. (2013). Hospital payment systems based on diagnosis-related groups: experiences in low-and middleincome countries. Bulletin of the World Health Organization, 91,
746-756. https://doi.org/10.2471/ blt.12.115931

27. Medeiros, J., \& Schwierz, C. (2015). Efficiency estimates of health care systems (Economic Papers 549). Brussels, Belgium: European Commission. Retrieved from https://ec.europa.eu/economy_finance/publications/economic_paper/2015/pdf/ecp549_en.pdf

28. Meng, Z., Hui, W., Cai, Y., Liu, J., \& Wu, H. (2020). The effects of DRGs-based payment compared with cost-based payment on inpatient healthcare utilization: A systematic review and meta-analysis. Health Policy, 124(4), 359-367. http://dx.doi.org/10.1016/j.healthpol.2020.01.007

29. Mihailovic, N., Kocic, S., \& Jakovljevic, M. (2016). Review of diagnosis-related group-based financing of hospital care. Health services research and managerial epidemiology, 3, 1-8. https://doi. org/10.1177/2333392816647892

30. Milcent, C. (2021). From downcoding to upcoding: DRG based payment in hospitals. International Journal of Health Economics and Management, 21(1), 1-26. https:// link.springer.com/article/10.1007/ s10754-020-09287-x

31. Negrini, D., Kettle, A., Sheppard, L., Mills, G. H., \& Edbrooke, D. L. (2004). The cost of a hospital ward in Europe. Journal of Health Organization and Management, 18, 195-206. https://doi. org/10.1108/14777260410548437

32. Nguyen, B. H., \& Zelenyuk, V. (2020). Aggregation of Outputs and Inputs for DEA Analysis of Hospital Efficiency: Economics, Operations Research and Data Science Perspectives (Working Paper Series No. WP11/2020). University of Queensland, Australia. Retrieved from https://economics.uq.edu.au/ files/23820/WP112020.pdf

33. Nistor, C. S., Stefanescu, C. A., \& Crisan, A.-R. (2017). Performance through efficiency in the public healthcare system-a dea approach in an emergent country. Studia Universitatis Babes-Bolyai Oeconomica, 62(1), 31-49. https://doi. org/10.1515/subboec-2017-0003 
34. Önen, Z., \& Sayın, S. (2018). Evaluating healthcare system efficiency of OECD countries: A DEA-based study. Operations research applications in health care management, 262, 141-158. http:// dx.doi.org/10.1007/978-3-31965455-3_6

35. Ozorovský, V. (2016). Zdravotnícky manažment a financovanie (1. vyd.). Bratislava: Wolters Kluwer.

36. Quentin, W., Schneller-Kreinsen, D., Blümel, M., Geissler, A., \& Busse, R. (2013). Hospital payment based on diagnosisrelated groups differs in Europe and holds lessons for the United States. Health Affairs, 32(4), 713723. https://doi.org/10.1377/ hlthaff.2012.0876

37. Quentin, W., Partanen, V-M., Brownwood, I., \& Klazinga, N.S. (2019). Measuring healthcare quality. Improving healthcare quality in Europe, 53, 31-32. Retrieved from https://www. researchgate.net/publication/339386881_Measuring healthcare_quality

38. Rizova, T. (2016). Global regional and marketing aspects of medical tourism in Bulgaria as an EU member country. Evraziyskoye Nauchnoye Obyedineniye, 1(4), 4548. Retrieved from https://elibrary. $\mathrm{ru} / \mathrm{item} \cdot \mathrm{asp}$ ?id=25958187

39. Setiawannie, Y., \& Rahmania, T. (2019). Performance measurement of public hospitals through the integration of SWOT and balanced scorecard. Jurnal Sistem dan Manajemen Industri, 3(2), 7688. https://doi.org/10.30656/jsmi. v3i2.1472

40. Sheaff, R., Morando, V., Chambers, N., Exworthy, M., Mahon, A., Byng, R., \& Mannion, R. (2020). Managerial workarounds in three European DRG systems. Journal of health organization and management, 34(3), 295-391. https://doi. org/10.1108/JHOM-10-2019-0295

41. Schmid, A., Cacace, M., Gotze, R., \& Rothgang, H. (2010). Explaining health care system change: problem pressure and the emergence of "hybrid" health care systems. Journal of Health Politics, Policy and
Law, 35(4), 455-486. https://doi. org/10.1215/03616878-2010-013

42. Schreyögg, J. (2019). Changes in Hospital Financing and Organization and their Impact on Hospital Performance. Oxford Research Encyclopedia: Economics and Finance. https://doi.org/10.1093/ acrefore/9780190625979.013.380

43. Stefko, R., Gavurova, B., \& Kocisova, K. (2018). Healthcare efficiency assessment using DEA analysis in the Slovak Republic. Health economics review, 8(1), 6 . https://doi.org/10.1186/s13561018-0191-9

44. Stehlíková, B. (2009). Metodologie výzkumu a statistická inference (9. vyd.). Brno: Mendelova lesnická a zemědělská univerzita.

45. Stephani, V., Quentin, W., \& Geissler, A. (2017). Beyond DRGbased hospital payment: How countries pay for variable, specialized and low volume care. European Journal of Public Health, 27(3). https://doi.org/10.1093/eurpub/ ckx187.188

46. Stewart. C. (2018). Medical tourism in Europe - Statistics \& Facts (Statistics Report). Retrieved from https://www.statista.com/ topics/3292/medical-tourism-ineurope

47. Talaghir, L. G., Gheonea, V., Rus, C. M., Cretu, C. M., \& Iconomescu, T. M. (2018). Statistical analysis of hospitalized morbidity indicators based on DRG in Romanian Public Hospitals. Revista de Cercetare si Interventie Sociala, 61, 163-186. Retrieved from https://www.proquest. com/openview/b02550ec82a5 9e4a4b6544378783bf3c/1?pqorigsite $=$ gscholar $\& \mathrm{cbl}=2031098$

48. Tan, S. S., Geissler, A., Serdén, L., Heurgren, M., van Ineveld, B. M. Redekop, W. K., \& van Roijen, L. H. (2014). DRG systems in Europe: variations in cost accounting systems among 12 countries. European Journal of Public Health, 24(6), 1023-1028. https:// doi.org/10.1093/eurpub/cku025

49. Toth, F. (2016). Classification of healthcare systems: Can we go further? Health Policy, 120(5),
535-543. https://doi.org/10.1016/j. healthpol.2016.03.011

50. Weber, A., \& Clerc, M. (2017). Deaths amenable to health care: Converging trends in the EU? Health Policy, 121(6), 644-652. https://doi.org/10.1016/j.healthpol.2017.03.017

51. WHO (2012). DRG-based payment systems in low- and middle income countries: Implementation experiences and challenges (Discussion Paper 1-2012). Retrieved from https://www.who.int/ health_financing/documents/ dp_01_2012_drg_based_payment_systems_in_lmic.pdf

52. WHO (2019). Targets and indicators for Health 2020. Retrieved from http://www.euro.who.int/ data/assets/pdf_file/0009/378945/ Targets4_EN_WEB.pdf

53. WHO (2000). Health systems: Improving performance (The World Health Report). Retrieved from https://www.who.int/whr/2000/ en/whr00_en.pdf?ua =1

54. Zolfagharian, M., Zolfagharian, M., Rajamma, R. K., Naderi, I., \& Torkzadeh, S. (2018). Determinants of medical tourism destination selection process. Journal of Hospitality Marketing \& Management, 27(7), 775-794. Retrieved from https://www.semanticscholar. org/paper/Determinants-ofmedical-tourism-destinationprocess-Zolfagharian-Rajamma/ efb930971c16dfd25cff570dc5dd2acb7bd99100 